\title{
Assessment of the Mechanical Properties of Marble and Granite Dust-High Impact Polystyrene Composites
}

\author{
Mohamed Mohamed Karbous", Ayman Abd El Wahab, Ramadan El Gamasy, \\ Mohamed Hazem Abdellatif
}

Design and Production Engineering Department, Ain Shams University, Cairo, Egypt

Email address:

mm.ibrahim@eng.asu.edu.eg (M. M. Karbous)

${ }^{*}$ Corresponding author

\section{To cite this article:}

Mohamed Mohamed Karbous, Ayman Abd El Wahab, Ramadan El Gamasy, Mohamed Hazem Abdellatif. Assessment of the Mechanical Properties of Marble and Granite Dust-High Impact Polystyrene Composites. Advances in Applied Sciences. Vol. 5, No. 3, 2020 , pp. 88-96. doi: 10.11648/j.aas.20200503.16

Received: August 25, 2020; Accepted: September 10, 2020; Published: October 22, 2020

\begin{abstract}
Experimental work has been carried out to study the effect of adding marble and Granite dust (MGD) on the mechanical properties of high impact polystyrene (HIPS). The selected wt.\% of MGD was 10, 20, 30, 40, 50 and 60. MGD was chemically treated by adding $2 \mathrm{wt} . \%$ stearic acid in an attempt to prevent agglomeration of the dust particles. Mechanical tests were conducted according to the ASTM standards to assess the bending strength and impact strength for both treated and untreated MGD-HIPS composites and also, Vickers hardness test was carried out. SEM analysis was also performed to interpret the results achieved throughout different tests. Surface modification of MGD particles using stearic acid caused better dispersion of MGD particles which lead to reduced agglomerations and this was observed through the SEM micrographs. Bending and impact strength of MGD-HIPS composite decreased by the increase of MGD content in the treated and untreated cases. On the other hand the increase of MGD content resulted in the increase of the surface hardness of treated and untreated MGD-HIPS composites. Surface treatment of the MGD particles using stearic acid had a greater effect on the surface hardness of the composite as the treatment allowed the production of a $70 \mathrm{wt} . \%$ MGD-HIPS composite plate which lead to an increase in the surface hardness of the composite by $130 \%$ compared to pure HIPS.
\end{abstract}

Keywords: Marble and Granite Dust, High Impact Polystyrene, Stearic Acid, Bending Strength, Impact Strength, Vickers Hardness, SEM

\section{Introduction}

About $70 \%$ of quarried marble and granite is wasted throughout its production cycle (from the quarrying site to the processing and polishing workshops) [1]. The waste is in the form of fragments and dust which is hazardous to the environment $[1,2]$. The piles of these wastes are left out in landfills which may cause critical health problems as well as the negative impact on the agricultural surroundings and living organisms [3-5]. So the usage of waste materials and converting it to safe \& useful materials for the environment and the society becomes a recent global demand.

A worldwide direction is to study the possibility of using marble and granite (MGD) in useful applications in order to minimize its highly negative impacts on the environment and health.

The Egyptian marble and granite industry showed massive growth over the last decade. Marble and granite products are considered as major Egyptian products for exportation. These products are quarried blocks, finished slabs and tiles. Figure 1 illustrates the exports of marble and granite products from 2008 to 2016. [6]

The area of Shaq el Thoban is one of the major areas in producing marble and granite in Cairo, Egypt. It contains quarries and processing factories and workshops. The Disposal of marble and granite waste takes place without any precautions. The wastes are usually dumped in areas surrounding the quarry. The wet dust (slurry) generated during the processing and polishing stages is left to dry and gets dumped in open air landfills [7]. This again may cause infertility of surrounding agricultural soils. It may lead to air 
and water pollution which affects human health and the life of any surrounding living creatures.

Marble is the most abundant and widespread type of metamorphic rock used for decoration purposes. It is a carbonate rock at which its original form is limestone (calcite$\mathrm{CaCO}_{3}$ ) and occasionally dolostone (dolomite- $\mathrm{CaMg}\left(\mathrm{CO}_{3}\right)_{2}$ ) which is re-crystallized over time after being subjected to high heat and pressure. Furthermore, marble contains other minerals such as quartz, mica and iron oxides which are the reason for giving marble its various colors and textures [8].

Granite is the most popular type of igneous rocks used for decoration and furnishing purposes. It is intrusive and acidic which gives it a granular texture and makes it strong and hard. Granite with its various types contain many minerals, mainly quartz (silica), feldspars (compounds consisting of aluminum, sodium and potassium) and others [8].

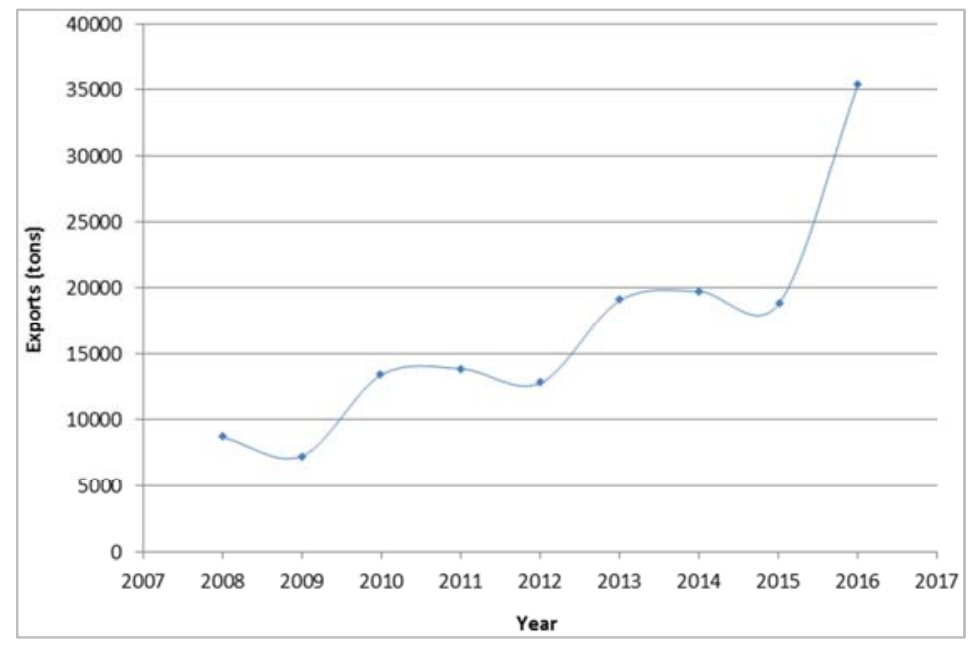

Figure 1. Egypt exports of marble and granite products [6].

Polystyrene (PS) is an amorphous aromatic (contains benzene rings) polymer made up of styrene monomers-Figure 2 [9].

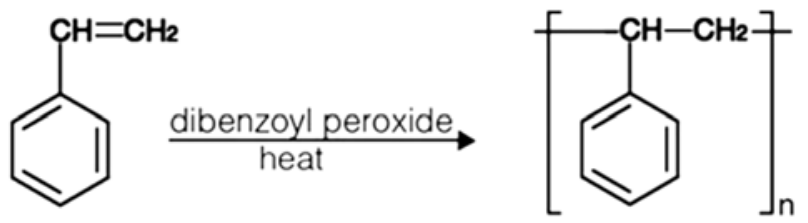

Figure 2. Chemical structure of Styrene (left) and Polystyrene (right).

PS is a thermoplastic polymer which gives the advantage of further recycling after processing and so environmental friendly, it biodegrades at a very slow rate and like all organic materials, carbon dioxide is given out through its burning. Furthermore, PS is available in the global market and highly consumed in the industry.

General purpose polystyrene (GPPS) is the commercial grade of polystyrene which is transparent, stiff, brittle and is very inexpensive. During polymerization, atactic polystyrene chains are formed leading to its amorphous structure. GPPS when modified with rubber particles produces high impact polystyrene (HIPS). [10-12]

HIPS is a non-transparent grade of polystyrene. It has higher impact resistance compared to GPPS. HIPS is produced by the polymerization of styrene monomers in the presence of up to $20 \%$ polybutadiene (PB) rubber particles (typically $1-10 \mu \mathrm{m}$ in size) [12]. The chemical structure of HIPS is illustrated in Figure 3 [13].

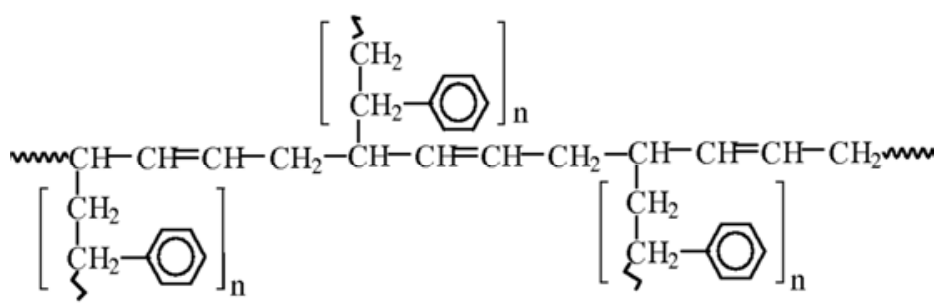

Figure 3. HIPS Chain with Polybutadiene backbone chain grafted with Polystyrene chains.

Increasing the rubber content causes further improvement in the polystyrene toughness, but consequently decreases its overall stiffness. Figure 4 represents a micrograph of the morphology of HIPS containing 8 wt-\% PB. 


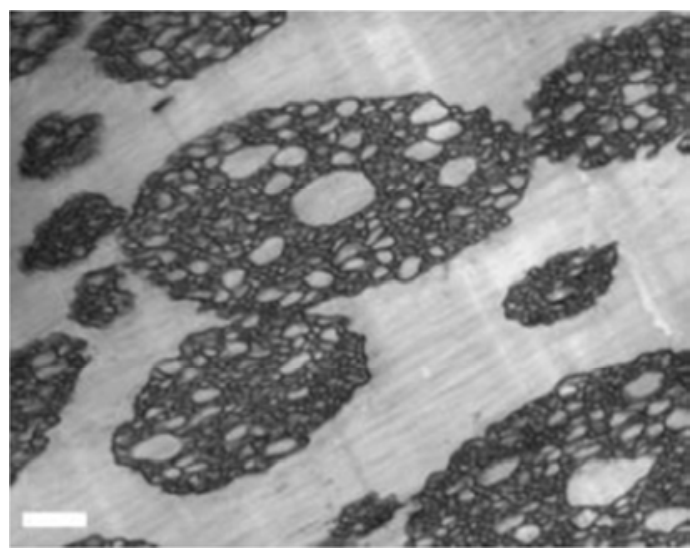

Figure 4. HIPS Morphology; PS (light color) and PB (dark color) [14].

In recent years, different researches were interested in investigating the effect of adding Calcium Carbonate $\left(\mathrm{CaCO}_{3}\right)$ as filler to different polymers to form polymeric composites with enhanced properties. Research also revealed that the usage of stearic acid as chemical treatment for $\mathrm{CaCO}_{3}$ particles would prevent its agglomeration in polymeric composites and cause better particles dispersion and so increase the overall surface area of the filler matrix interface resulting in better impact resistance and larger elongations at fracture of composites [15].

It was proposed to use marble dust as a source of $\mathrm{CaCO}_{3}$ as it is one of its main constituents [16]. This means that MGD can play the role of $\mathrm{CaCO}_{3}$ directly in polymeric composites.

The objective of this research is to study the effect of adding treated and untreated MGD on the mechanical properties of HIPS.

\section{Experimental Work}

\subsection{Materials}

The High Impact Polystyrene (HIPS) used as matrix (GPPC HIPS 350 HF) was supplied by Grand Pacific Petrochemicals Corp., Taiwan. The main specifications of the HIPS polymer used are listed in Table 1 as provided by the supplier.

Table 1. GPPC HIPS 350 HF specifications.

\begin{tabular}{lll}
\hline Property & Data & Unit \\
\hline Melt Flow Rate & 7.7 & $\mathrm{~g} / 10 \mathrm{~min}$ \\
Specific Gravity & 1.05 & \\
Tensile Strength (at yield) & 3 & $\mathrm{psi} \times 10^{3}$ \\
Tensile Elongation & 47 & $\%$ \\
Rockwell Hardness & 54 & $\mathrm{M}-$ Scale \\
Vicat Softening Temperature & 211 & ${ }^{\circ} \mathrm{F}$ \\
\hline
\end{tabular}

The Marble and Granite Dust (MGD) was collected from different marble and granite workshops in Shaq el Thoban, Egypt.

\subsection{MGD and HIPS Preparation}

MGD was sieved using five sieves with different mesh sizes as shown in Table 2. The particle size distribution is listed in Table 3. The particle size used in the preparation of the MGD-HIPS composite had a top cut of $180 \mu \mathrm{m}$ in size, as it was the most dominant size. The MGD and HIPS were placed in an oven and dried at $80{ }^{\circ} \mathrm{C}$ for 24 hours.

Table 2. Sieves sizes.

\begin{tabular}{lll}
\hline Sieve number & Mesh size & Opening size $(\boldsymbol{\mu m})$ \\
\hline 1 & 20 & 850 \\
2 & 28 & 600 \\
3 & 40 & 425 \\
4 & 50 & 300 \\
5 & 80 & 180 \\
\hline
\end{tabular}

Table 3. Particle size distribution.

\begin{tabular}{ll}
\hline Particle size $(\boldsymbol{\mu m})$ & Distribution $(\%)$ \\
\hline$>850$ & 3.5 \\
$850-600$ & 1.5 \\
$600-425$ & 1.5 \\
$425-300$ & 1.5 \\
$300-180$ & 4 \\
$<180$ & 88 \\
\hline
\end{tabular}

\subsection{Chemical Treatment of MGD}

The procedure used for chemical treatment of MGD followed the dry modification method described by Slavica R. Mihajlović et al. [17]. It involved the surface modification of $\mathrm{CaCO}_{3}$ particles contained inside MGD using stearic acid.

The procedure was as follows; add $2 \mathrm{~g}$ of stearic acid to every $100 \mathrm{~g}$ of dried MGD and mix them for 10 minutes at a temperature of $70^{\circ} \mathrm{C}$ using a mixing speed of $200 \mathrm{rpm}$. The mixing cavity had a volume of $500 \mathrm{ml}$.

\subsection{MGD-HIPS Composite Preparation}

The dried HIPS was placed inside the cavity of a thermal mixer for 15 minutes at $120^{\circ} \mathrm{C}$ in order to reach its plasticity phase. Next, the dried untreated or treated MGD was added in certain $w t \%$ to the HIPS and then mixed using a mixing speed of $60 \mathrm{rpm}$ until a homogeneous paste was formed. The MGD percentage was varied where 10, 20, 30, 40, 50 and 60 wt.\% were used. The mixing time varied depending on the amount of dust added; the higher the amount, the longer the mixing time was. The mixing time varied from 30 to 50 minutes.

The formed paste was then removed and placed inside the die cavity of a hydraulic press having a capacity of 25 tons and pressed at approximately 110 bar specific pressure for 10 minutes at a temperature of $180^{\circ} \mathrm{C}$. The plate was cooled to room temperature to produce untreated or treated MGDHIPS composite plates.

The Dimensions of the produced MGD-HIPS composite plate were $200 \times 200$ and thickness of approximately $10 \mathrm{~mm}$. It is also worth to be mentioned that the addition of stearic acid to MGD contributed to the success of producing 70 wt. $\%$ composite plates.

\subsection{Testing}

a. Three Point Bending Test 
Three point bending test was conducted according to the ASTM D790 standard. Test specimens were prepared and tested using a $10 \mathrm{kN}$ universal testing machine with a cross head speed of $2 \mathrm{~mm} / \mathrm{min}$. The test span length was set to 150 $\mathrm{mm}$.

Figure 5 shows a typical load-displacement curve for the bending test.

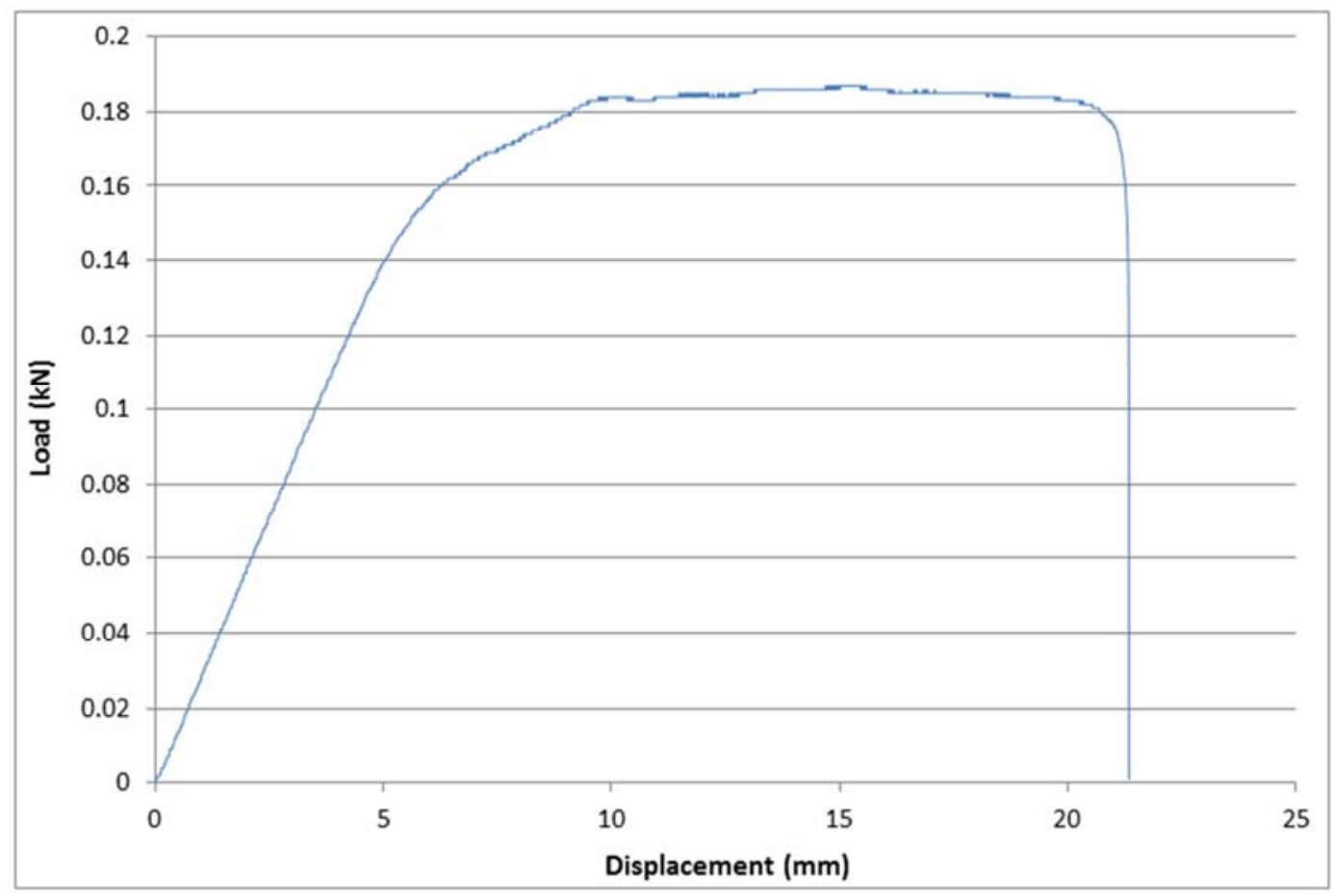

Figure 5. Load-displacement curve for 30 wt.\% untreated MGD bending specimen.

The bending strength $\sigma$ could be calculated from the following formula;

$$
\sigma=\frac{3 F L}{b t^{2}}
$$

Where $F$ is the maximum load subjected to the specimen, $L$ is the set span length, $b$ and $t$ are the specimen width and thickness respectively. The bending test specimen is illustrated schematically in Figure 6. The maximum load is obtained from the load-displacement curves averaged for five specimens.

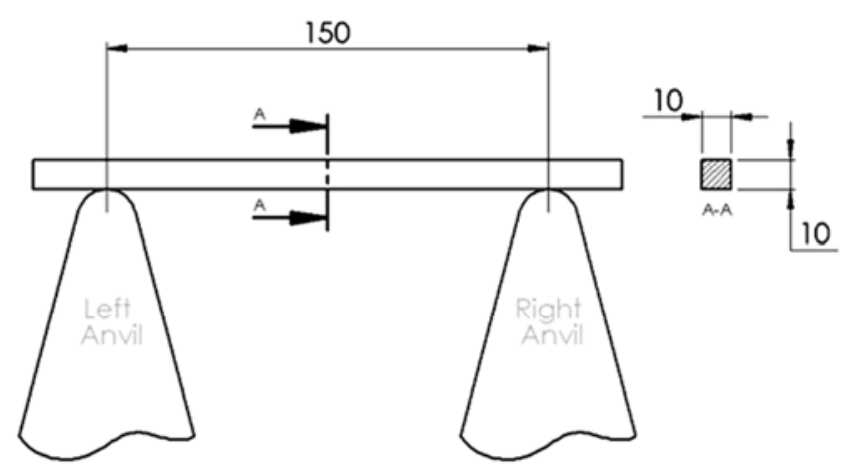

Figure 6. Schematic illustration of bending test specimen (all dimensions in $\mathrm{mm})$.

\section{b. Charpy Impact Test}

Charpy impact test was conducted according to the ASTM
D6110 standard. Test specimens were prepared and tested using a pendulum with test energy of $4 \mathrm{~J}$ at a speed of 3.5 $\mathrm{m} / \mathrm{s}$.

The free $\beta_{f}$ and actual $\beta_{a}$ impact angles were measured to calculate the absorbed energy $E_{s}$ by each specimen using the following formula;

$$
E_{s}=\text { Pendulum energy }\left(\cos \beta_{f}-\cos \beta_{a}\right)
$$

The impact strength $I$ could be calculated from the following formula;

$$
I=\frac{E_{s}}{b \times t}
$$

Where $b$ is the depth of the specimen after the notch and $t$ is the specimen width. The impact test specimen is illustrated schematically in Figure 7.

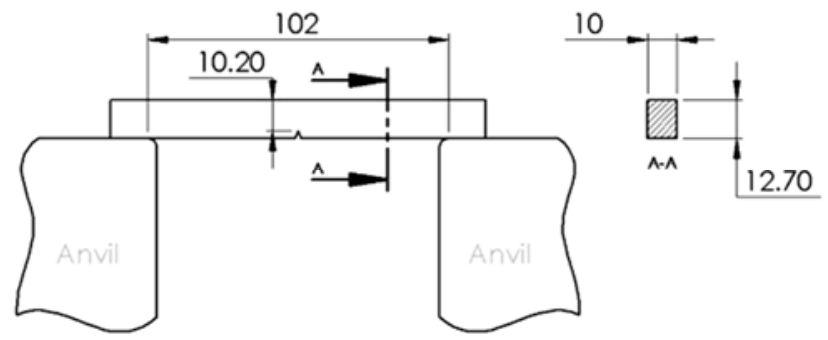

Figure 7. Schematic illustration of impact test specimen (all dimensions in $\mathrm{mm}$ ). 


\section{c. Hardness Test}

Hardness test was conducted according to the ASTM E384 standard. Test specimens were prepared and tested using a Vickers indenter with a test load of 300 gram force, loaded for $15 \mathrm{sec}$.

The indentation produced had a square shape projection. The diagonals of the projection were measured and averaged to calculate the mean diagonal length $d$ for each specimen indentation. The test load $P$ and the mean diagonal $d$ were used to calculate Vickers hardness number $H V$ using the following formula;

$$
H V=1854.4 \times \frac{P}{d^{2}}
$$

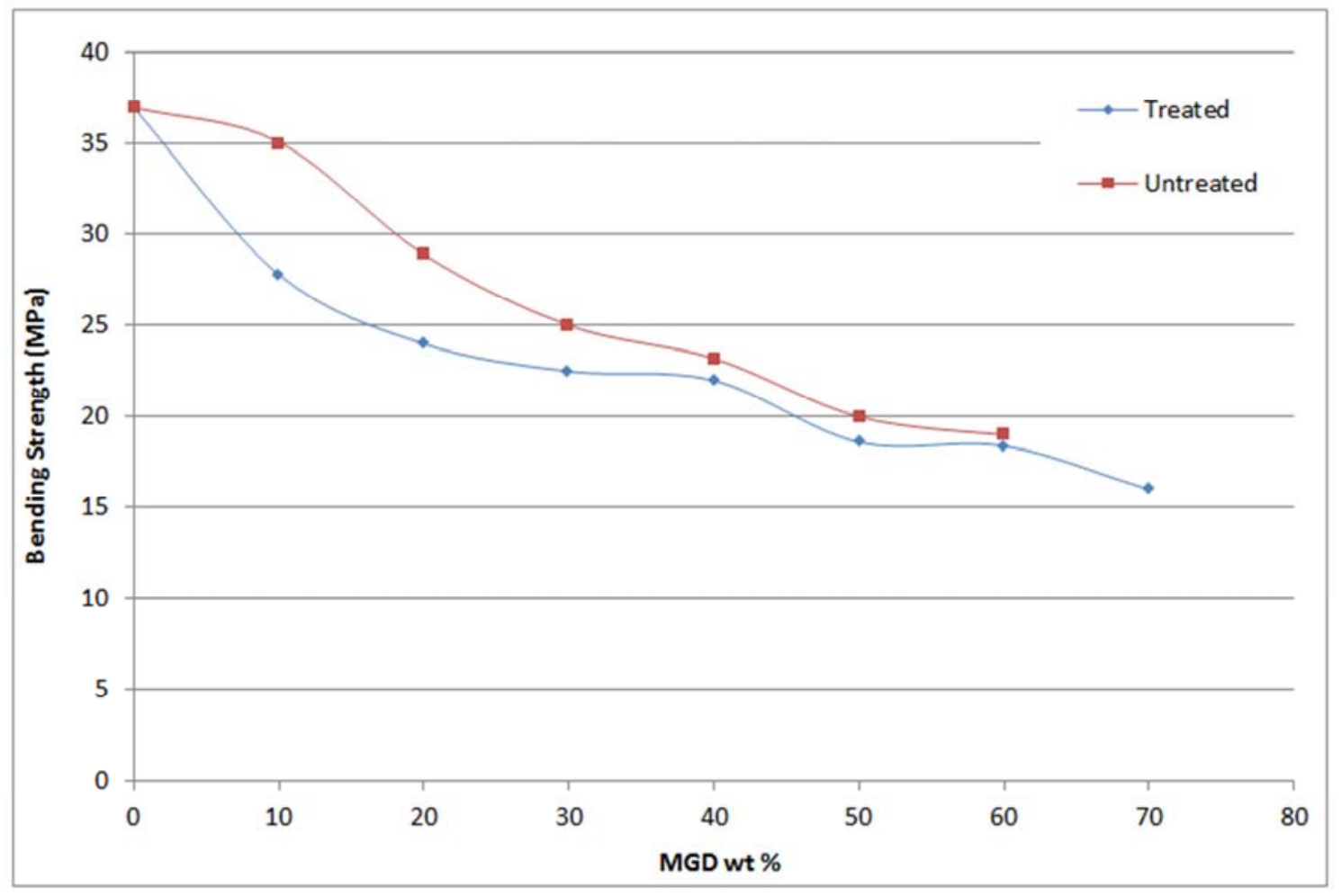

Figure 8. Effect of MGD wt\% on the bending strength of treated and untreated HIPS composites.

\section{Results and Discussion}

\subsection{Bending Strength}

The results of the three point bending test obtained are shown in Figure 8. The figure shows the effect of varying the MGD wt. $\%$ on the bending strength of the treated and untreated MGD-HIPS composites. It is observed that the bending strength decreases by the increase of MGD content in the treated and untreated cases due to the brittleness of MGD. The decrease in bending strength of untreated composites by the increase of MGD wt $\%$ was due to the weak interface formed between the MGD particles and the HIPS matrix as shown in Figure 9.

Furthermore, treated MGD-HIPS composites have lower bending strength values compared to the untreated composites at the same MGD wt.\%. The reason is that stearic acid creates a coating around the MGD particles without any interaction with the surrounding HIPS matrix which leads to weaker particle-matrix interface [18].

The percentage reduction of bending strength $w$. r. t. pure HIPS for treated and untreated MGD-HIPS composites is calculated and represented in Table 4. It was noticed that the passive effect of stearic acid on the bending strength of the fabricated composites decreased at higher MGD wt.\%.

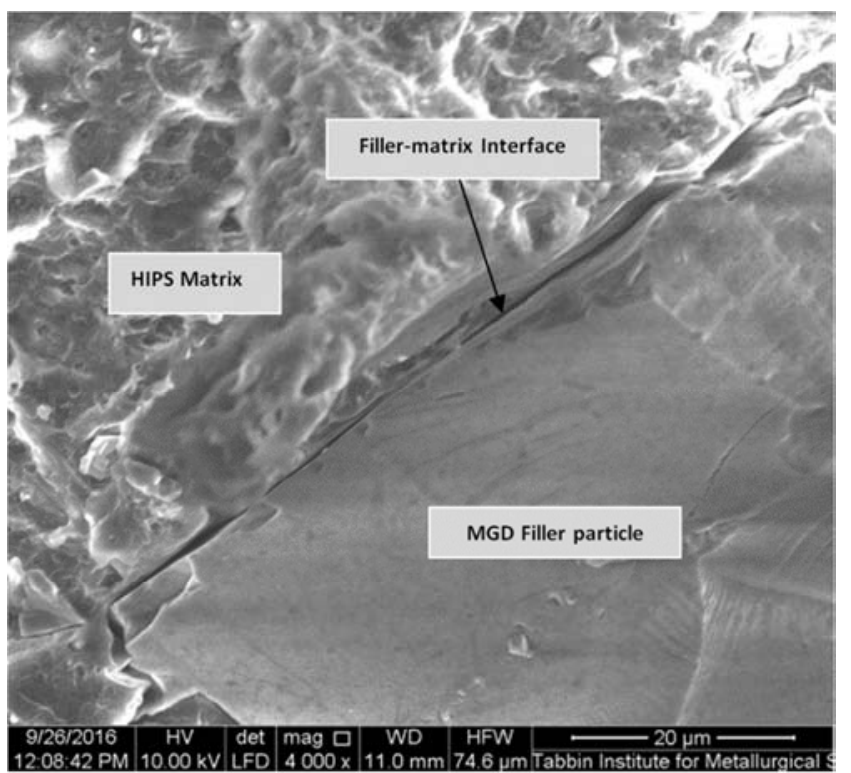

Figure 9. SEM micrograph of the fracture surface of an untreated $10 \mathrm{wt} \%$ $M G D$ bending specimen showing the filler-matrix interface. 
Table 4. Precentage reduction of bending strength w. $r$. t. pure HIPS by increasing $M G D$ wt\%.

\begin{tabular}{llll}
\hline \multirow{2}{*}{ MGD wt\% } & \multicolumn{2}{l}{ Reduction (\%) } & \multirow{2}{*}{ Difference (\%) } \\
\cline { 2 - 3 } & Untreated & Treated & \\
\hline 10 & 5.1 & 24.9 & 19.8 \\
20 & 21.9 & 35.1 & 13.2 \\
30 & 32.4 & 39.2 & 6.8 \\
40 & 37.3 & 40.5 & 3.2 \\
50 & 45.9 & 49.7 & 3.8 \\
60 & 48.6 & 49.7 & 1.1 \\
70 & & 56.7 & \\
\hline
\end{tabular}

Figure 10 represents a SEM micrograph showing the fracture surface of a bending test specimen containing 60 wt.\% treated MGD. It is observed that the addition of stearic acid decreased the agglomeration of MGD particles and so enhanced the distribution and dispersion of the filler particles within the matrix. This increases the surface area of the MGD particles which has bad adhesion with the HIPS matrix, resulting in reduced bending strength, but on the other hand results in improved the impact strength of the composites. Additional effect of stearic acid is the reduction of polymer viscosity so more MGD particles could be successfully added to produce the $70 \mathrm{wt} \%$ MGD-HIPS composite plate.

Figure 11 below represents another micrograph but this time showing the fracture surface of a $10 \mathrm{wt} . \%$ untreated
MGD bending specimen at much higher magnification. The figure features a point of agglomeration of the MGD particles which once again shows the effect of the stearic acid treatment.

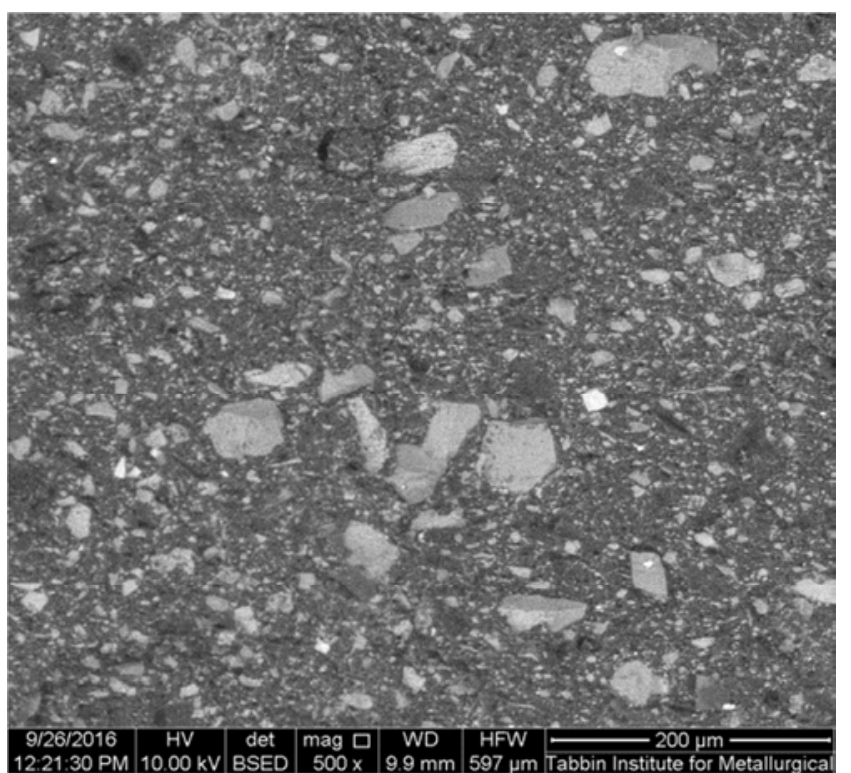

Figure 10. SEM micrograph of the fracture surface of a treated $60 \mathrm{wt} \%$ $M G D$ bending specimen.

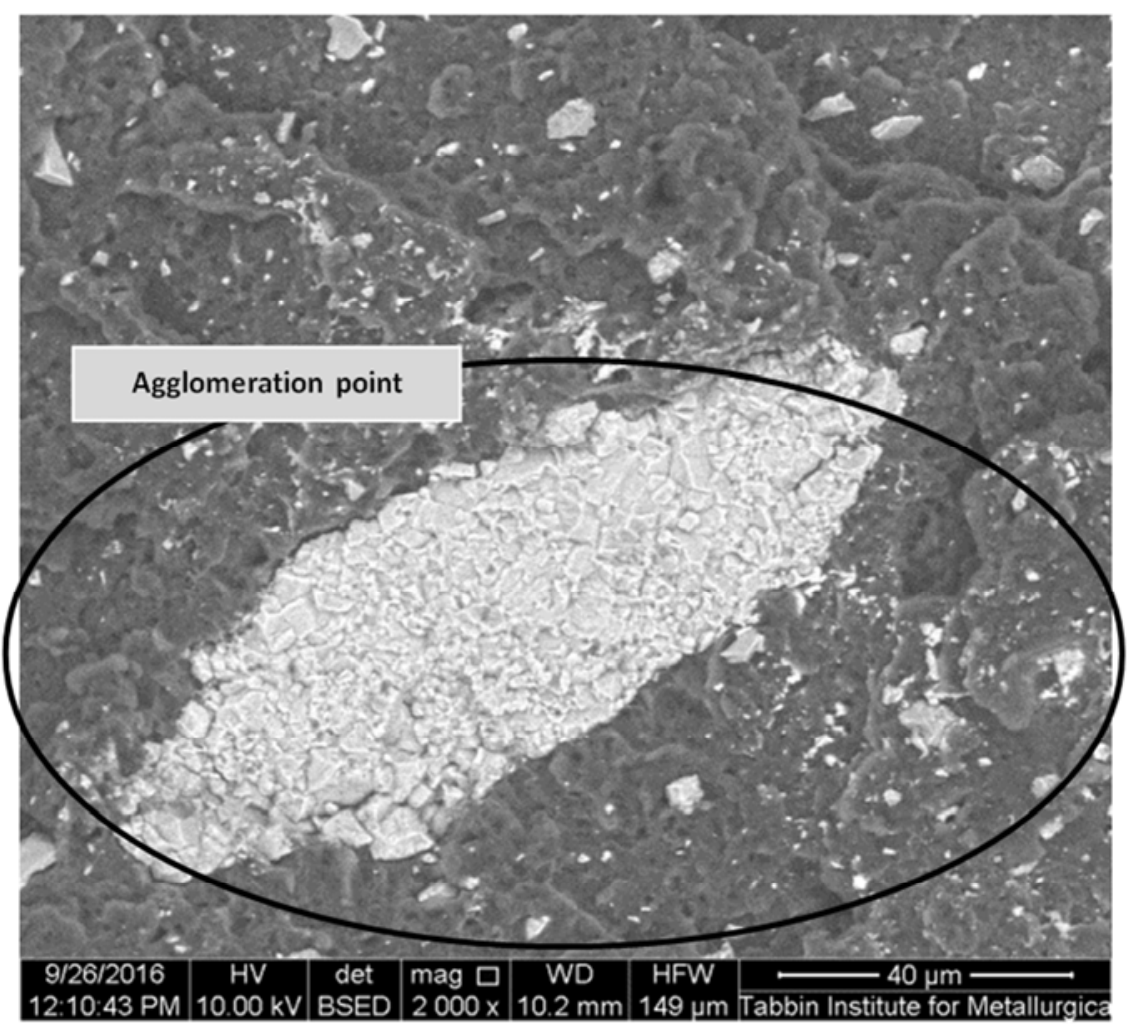

Figure 11. SEM micrograph of the fracture surface of a $10 \mathrm{wt} \%$ untreated MGD bending specimen showing an agglomeration point.

\subsection{Impact Strength}

The results of charpy impact test obtained are shown in Figure 12. The figure illustrates the effect of varying the MGD wt.\% on the impact strength of treated and untreated MGDHIPS composites. It is observed that the decrease of impact strength of treated and untreated composites is due to the increase of the brittle MGD particles which replaces the energy 
absorbing HIPS matrix. It is also expected that stronger interface between HIPS and MGD particles may cause further decrease in the impact strength of the composite, which was the case for untreated MGD-HIPS composites.

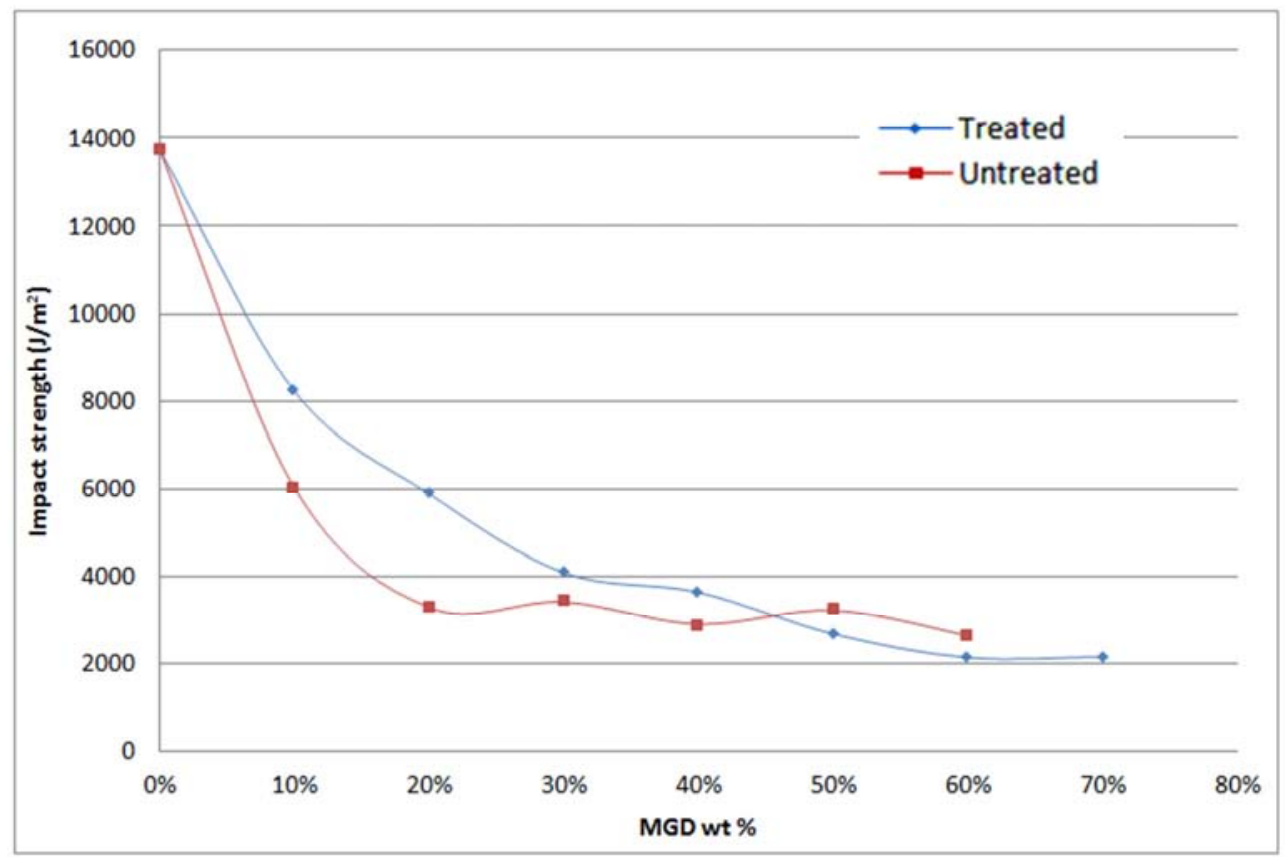

Figure 12. Effect of MGD wt\% on the Impact resistance of treated and untreated HIPS composites.

The decrease of impact strength may also be attributed to the formation of internal microcracks as shown in Figure 13.

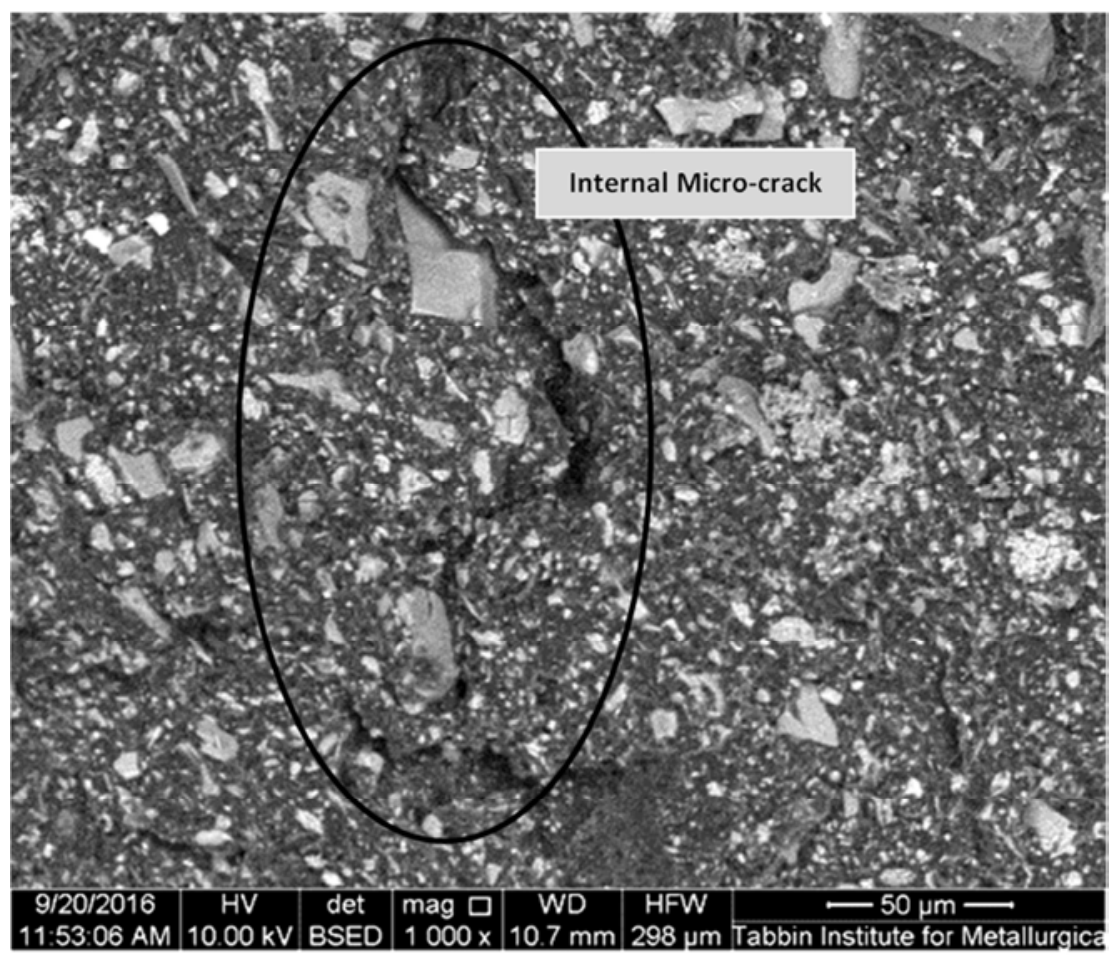

Figure 13. SEM micrograph of the fracture surface of a untreated $60 \mathrm{wt} \% \mathrm{MGD}$ impact specimen.

\subsection{Hardness}

The results of Vickers hardness test is shown in Figure 14. The figure illustrates the effect of varying the MGD $\mathrm{wt} \%$ on the surface hardness of treated and untreated MGD-HIPS composites. It is observed that the increase of MGD content resulted in increase of the surface hardness of treated and untreated MGD-HIPS composites. The increase of the surface hardness of the composite may be assigned to the harder nature of marble and granite compared to HIPS. So 
the usage of MGD particles as filler inside the HIPS matrix would rationally increase the overall hardness of the composite.

The addition of stearic acid has passive effect on the surface hardness of the composite. It only allowed the production of the $70 \mathrm{wt} \%$ MGD-HIPS composite plate which leads to increasing the hardness of the composite by $141 \%$ compared to pure HIPS as illustrated in Table 5.

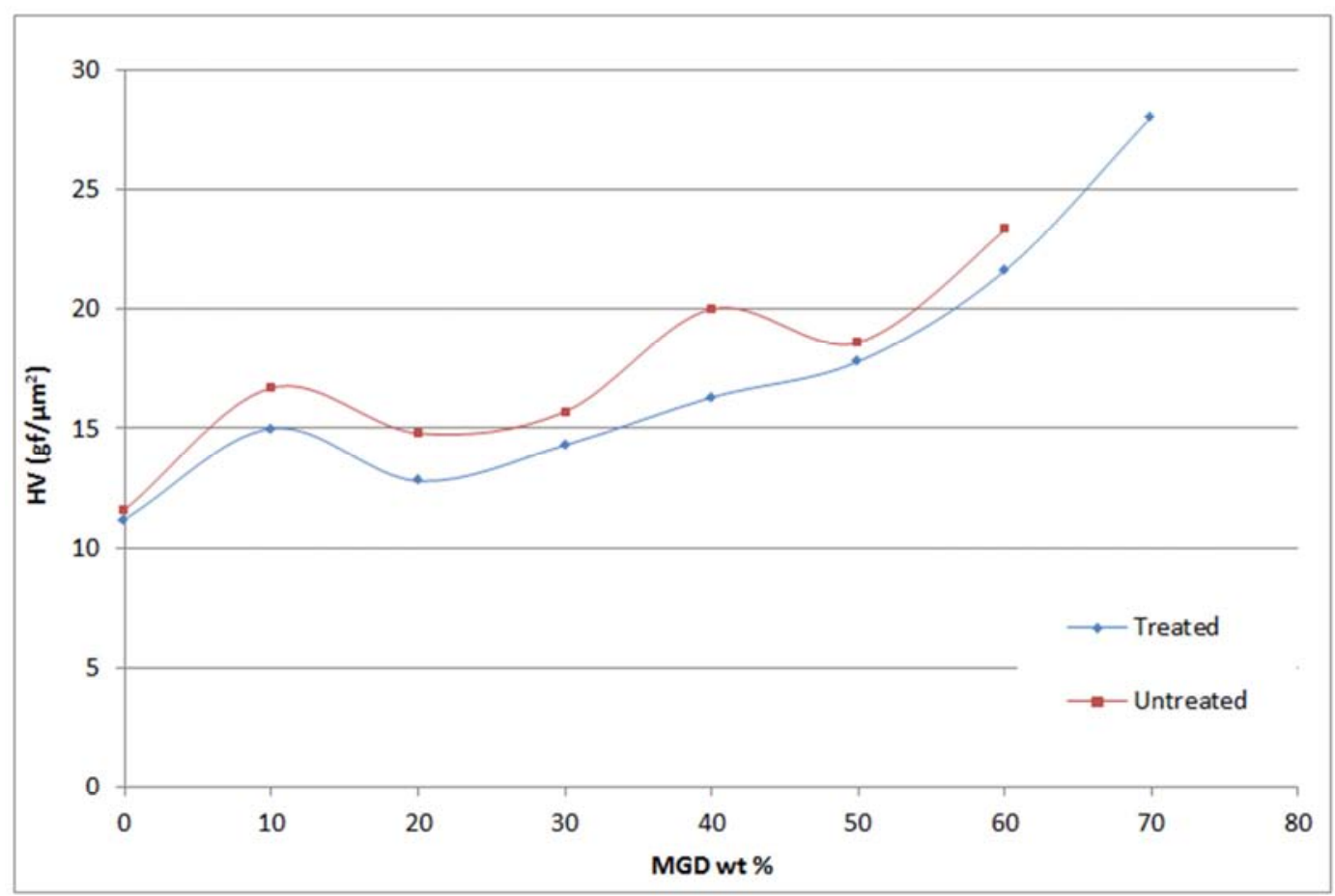

Figure 14. Effect of MGD wt\% on the surface hardness of treated and untreated HIPS composites.

Table 5. Precentage increase of impact strength w. r. t. pure HIPS by increasing $M G D w t \%$.

\begin{tabular}{lll}
\hline \multirow{2}{*}{ MGD wt\% } & Increase (\%) & \\
\cline { 2 - 3 } & Untreated & Treated \\
\hline 10 & 44 & 29 \\
20 & 26 & 10 \\
30 & 35 & 23 \\
40 & 72 & 41 \\
50 & 60 & 53 \\
60 & 101 & 86 \\
70 & & 141 \\
\hline
\end{tabular}

\section{Conclusions}

Surface modification of MGD particles using stearic acid caused better dispersion of MGD particles which lead to reduced agglomerations. Furthermore, it caused a reduction in the polymer's viscosity so more MGD particles could be successfully added which lead to the production of a $70 \mathrm{wt} . \%$ MGD-HIPS composite plate.

Bending strength of MGD-HIPS composite decreased by the increase of MGD content in the treated and untreated cases. The decrease in bending strength of untreated composites by the increase of MGD wt.\% was due to the weak interface formed between the MGD particles and the HIPS matrix. Treated MGD-HIPS composites showed lower bending strength values compared to the untreated composites at the same MGD wt.\%. The reason is that stearic acid created a coating around the MGD particles without any interaction with the surrounding HIPS matrix which lead to weaker particle-matrix interface.

Decrease of impact strength of treated and untreated composites was sighted. This was caused by the increase of the brittle MGD particles which replaced the energy absorbing HIPS matrix. Untreated MGD-HIPS composites had less impact strength compared to treated MGD-HIPS composites due to the stronger interface between HIPS and MGD particles.

The increase of MGD content resulted in the increase of the surface hardness of treated and untreated MGD-HIPS composites. Surface treatment of the MGD particles using stearic acid had a passive effect on the surface hardness of the composite. Yet, the treatment allowed the production of a 70 wt.\% MGD-HIPS composite plate which lead to an increase in the surface hardness of the composite by $130 \%$ compared to pure HIPS.

\section{References}

[1] M. Y. Celik, "Geological and technical characterisation of Iscehisar (Afyon-Turkey) marble deposits and the impact of marble waste on environmental pollution," Journal of Environmental Management 87, pp. 106-116, 2008.

[2] S. M. El-Haggar, "Industrial Solid Wastes Utilization and Disposal," in Environmental Engineering, Sixth Edition. Environmental Health and Safety for Municipal Infrastructure, Land Use and Planning, and Industry, New Jersey, John Wiley \& Sons, Inc., 2009. 
[3] M. I. El-Gammal, "Health Risk Assessment of Marble Dust at Marble Workshops," Nature and Science, 2011.

[4] R. A. Hamza, "Marble and Granite Waste: Characterization and Utilization in Concrete Bricks," International Journal of Bioscience, Biochemistry and Bioinformatics, vol. 1, no. 4, 2011.

[5] M. Ozcelik, "Environmental pollution and its effect on water sources from marble quarries in western Turkey," Environ Earth Sci, 2016.

[6] Central Agency for Public Mobilization and Statistics, "Egyptian exports of marble and granite from 2008 to 2016," Cairo, 2017.

[7] R. A. Eid, Approaching Industrial and Environmental Reform for Shaq al Thuban Marble and Granite Industrial Cluster, Cairo: American University in Cairo, 2011.

[8] D. Zou, Theory and Technology of Rock Excavation for Civil Engineering, Hong Kong: Springer Nature, 2017.

[9] J. Massy, A Little Book about BIG Chemistry, Springer Nature, 2017.

[10] M. Akay, Introduction to Polymer Science and Technology, Ventus Publishing ApS, 2012.

[11] H. F. Mark, Encyclopedia of Polymer Science and Technology, Wiley, 2007.
[12] M. Alger, Polymer Science Dictionary, Towcester, Northants UK: Springer Nature, 2017.

[13] J. M. Sosa, "Methods for Production of High Impact Polystyrene". United States Patent US 2011/0201757 A1, 18 August 2011.

[14] F. Soriano-Corral, "Synthesis and Characterization of High Impact Polystyrene from a Heterogeneous Styrene-RubberPolystyrene Solution: Influence of PS Concentration on the Phase Inversion, Morphology and Impact Strength," Macromolecular Symposia, pp. 177-183, 2013.

[15] Y. WANG, POLYMER COMPOSITE, vol. 25, no. 5, pp. 451460, 2004.

[16] A. Mashaly, "Characterization of The Marble Sludge of The Shaq El Thoaban Industrial Zone, Egypt and Its Compatibility for Various Recycling Applications," Australian Journal of Basic and Applied Sciences, vol. 6, no. 3, 2012.

[17] S. R. Mihajlović, "Mechanism of stearic acid adsorption to calcite," Powder Technology, vol. 245, p. 208-216, 2013.

[18] R. Rothon, in Fillers for Polymer Applications, Switzerland, Springer Nature, 2017. 